\title{
Graphene foam functionalized with electrodeposited nickel hydroxide for energy applications
}

\author{
Sandra Ruiz-Gómez ，Alberto Boscá ， Lucas Pérez ～, Jorge Pedrós , Javier Martínez \\ Antonio Páez , Fernando Calle
}

\begin{abstract}
A B S T R A C T
The need of new systems for the storage and conversion of renewable energy sources is fueling the research in supercapacitors. In this work, we propose a low temperature route for the synthesis of electrodes for these supercapacitors: electrodeposition of a transition metal hydroxide- $\mathrm{Ni}(\mathrm{OH})_{2}$ on a graphene foam. This electrode combines the superior mechanical and electrical properties of graphene, the large specific surface area of the foam and the large pseudocapacitance of $\mathrm{Ni}(\mathrm{OH})_{2}$. We report a specific capacitance up to $900 \mathrm{~F} / \mathrm{g}$ as well as specific power and energy comparable to active carbon electrodes. These electrodes are potential candidates for their use in energy applications.
\end{abstract}

\section{Introduction}

The environmental problems arisen from the use of fossil fuels have strengthened the search for the storage and conversion of renewable energy sources. Electrochemical capacitors, also known as supercapacitors, have been proposed as novel energy storage devices because they have not only shorter charging time than batteries, but also higher energy density than conventional dielectric capacitors [1-5]. Supercapacitors are promising energy storage devices as well as power supplies for systems requiring high power density and long cycle life as electric vehicles and portable electronic devices [6]. Considering the mechanism involved in the energy storage process, supercapacitors can be divided into two families: electrical double layer supercapacitors, based on quick adsorption/desorption process on the surface of the electrode; and pseudocapacitors, in which the capacitance is originated on a fast faradaic charge transfer reaction $[7,8]$.

Transition-metal oxides as well as conductive polymers can be used as active materials in asymmetrical supercapacitors $[9,10]$. Among the used materials to date, ruthenium oxides have been extensively studied as active electrode materials as they can show a capacitance as large as $863 \mathrm{~F} / \mathrm{g}$ in acidic electrolytes [11]. However, ruthenium is an expensive material and, although its electrochemical properties are nearly ideal, has limited possibilities for commercialization. Hence, much effort has been aimed at searching for alternative inexpensive electrode materials with good pseudocapacitance behavior as cobalt, nickel and manganese oxides and hydroxides because of their reversible redox transition they show at the electrode surface [12-14]. In this sense, $\mathrm{Ni}(\mathrm{OH})_{2}$ has attracted increasing attention over the past decades as potential material for supercapacitors due to the extraordinary high value of the capacitance that can theoretically be achieved (2082 F/g) [15-17]. Moreover, it is a non-expensive and environment-friendly material.

However, there are still a great number of challenges to overcome in order to get high capacity $\mathrm{Ni}(\mathrm{OH})_{2}$ electrodes. It is well accepted that the overall performance of an electrode material depends not only on the microstructure but also on the conductivity of the electrode [18-20], and $\mathrm{NiOH}_{2}$ has a poor electrical conductivity $\left(10^{17} \mathrm{~S} / \mathrm{cm}\right)$ [21], which is possibly the major drawback of this material for being used as active material. Fortunately, the conductivity of the electrode can be improved by introducing carbon-based materials [6,22,23]. Among them, graphene has attracted tremendous attention in the last years due to its unique properties over other carbon nanomaterials in view of its application in supercapacitors. These unique properties include a large electrical conductivity, high specific surface area, high mechanical flexibility and chemical stability [24,25]. Recently, three-dimensional (3D) graphene has been proposed as a candidate for energy applications. This 3D graphene, in the form of graphene foam, provides a free- 
standing 3D interconnected network of graphene which keeps the main properties of graphene. These foams are perfect candidates to serve as a robust scaffold to be functionalized with a metal oxide to get a large pseudocapacitance [26-28]. This combination of graphene and a transition oxide metal merges the previously mentioned advantages of both components [29-31].

In this work we propose a low temperature route to functionalize graphene foams to be used as an electrode in electrochemical supercapacitors. The functionalization is based on electrochemical synthesis of $\mathrm{NiOH}_{2}$ which is incorporated to a free standing graphene foam, previously fabricated using Chemical Vapor Deposition (CVD) of graphene on a Ni foam.

\section{Material and methods}

The 3D graphene foam is grown by using a $\mathrm{Ni}$ foam as the catalytic substrate in a CVD process. After growth, the Ni foam is removed to obtain a free-standing 3D graphene foam. All the measured foams are squared samples $10 \times 15 \mathrm{~mm}^{2}$ in size approximately. The electrodeposition of the $\mathrm{Ni}(\mathrm{OH})_{2}$ coatings on the graphene foam was performed using an Ecochemie Autolab PGSTAT 302N potentiostat/ galvanostat in a three-electrode pyrex cell using a Pt gauze as counter electrode, a $\mathrm{Ag} / \mathrm{AgCl}$ electrode (BASi) as reference and the graphene foam as working electrode. For that, an ohmic contact was done in the graphene foam using conductive silver paint. The contact was electrically isolated from the solution using a chemically resistant epoxy (Loctite $3423 \mathrm{AB})$. The electrolyte contains $0.2 \mathrm{M} \mathrm{Ni}(\mathrm{NO})_{3} \cdot 6 \mathrm{H}_{2} \mathrm{O}$ and $0.2 \mathrm{M}$ hexamethylenetramine $\left(\mathrm{C}_{6} \mathrm{H}_{12} \mathrm{~N}_{4}\right)$. All the chemicals were of analytical grade, used without further purification and were mixed in deionized water.

The mass of the functionalized electrode (graphene foam $+\mathrm{Ni}(\mathrm{OH})_{2}$ layer) was measured after drying the sample in air at room temperature, being their average mass of the electrodes $3.5 \mathrm{mg}$ approximately. The crystalline structure of the $\mathrm{Ni}(\mathrm{OH})_{2}$ was examined by $\mathrm{X}$-ray diffraction (XRD) in a Bragg-Brentano configuration using a PANalytical X'Pert MPD diffractometer using $\mathrm{Cu}-\mathrm{K} \alpha$ radiation. The surface morphology and microstructure were examined by Scanning Electron Microscopy (SEM). All the electrochemical measurements were performed in a conventional three-electrode configuration in a $3 \mathrm{M} \mathrm{KOH}$ aqueous solution. Cyclic voltammetry (CV) and galvanostatic charge/discharge tests were performed using the Ecochemie Autolab PGSTAT potentiostat/galvanostat. All the reported values are normalized by the mass of the full electrode (graphene foam + functionalization).

\section{Results and discussion}

Fig. 1.a shows graphene foam before functionalization. Due to the excellent conductivity and mechanical properties of graphene, this foam is a perfect scaffold for the electrode: it can be easily manipulated and provides an excellent charge-extraction performance. In addition, the ripples and wrinkles of graphene provide a large surface area, which increase the capacitance of the electrode.

The foams have been functionalized via potentiostatic electrodeposition with a cathodic potential of $-0.5 \mathrm{~V}$ ( vs $\mathrm{Ag} / \mathrm{AgCl}$ ) at $70^{\circ} \mathrm{C}$. To remove the air trapped inside the foam, ensuring that the electrolyte penetrates in the pores of the foam, the graphene foam was immersed in the electrolyte and kept under vacuum for $1 \mathrm{~h}$ just before electrode positing. We grew a series of samples changing the deposition time from 1 to $6 \mathrm{~h}$. The thickness of the coating, measured by SEM in cross-section view, increases from less than $1 \mu \mathrm{m}$ for $1 \mathrm{~h}$ to more than $3 \mu \mathrm{m}$ for $6 \mathrm{~h}$. Fig. 1.b to d shows SEM images of the 3D graphene foam coated with a thin nickel hydroxide layer. The functionalization clearly changes the surface morphology of the foam. There are nickel hydroxide nanoflakes covering the graphene and forming a compact but porous film, with a petal-like structure. In addition to the pseudocapacitance of the hydroxide, this porous structure increases the surface area, which is expected to increase the capacitance. We have not found any qualitative difference in the morphology for all the samples grown in this work. The procedure for the synthesis of the electrodes is similar to the one described by Cao and colaborators [31]. However, it is important to note that, in our case, no further
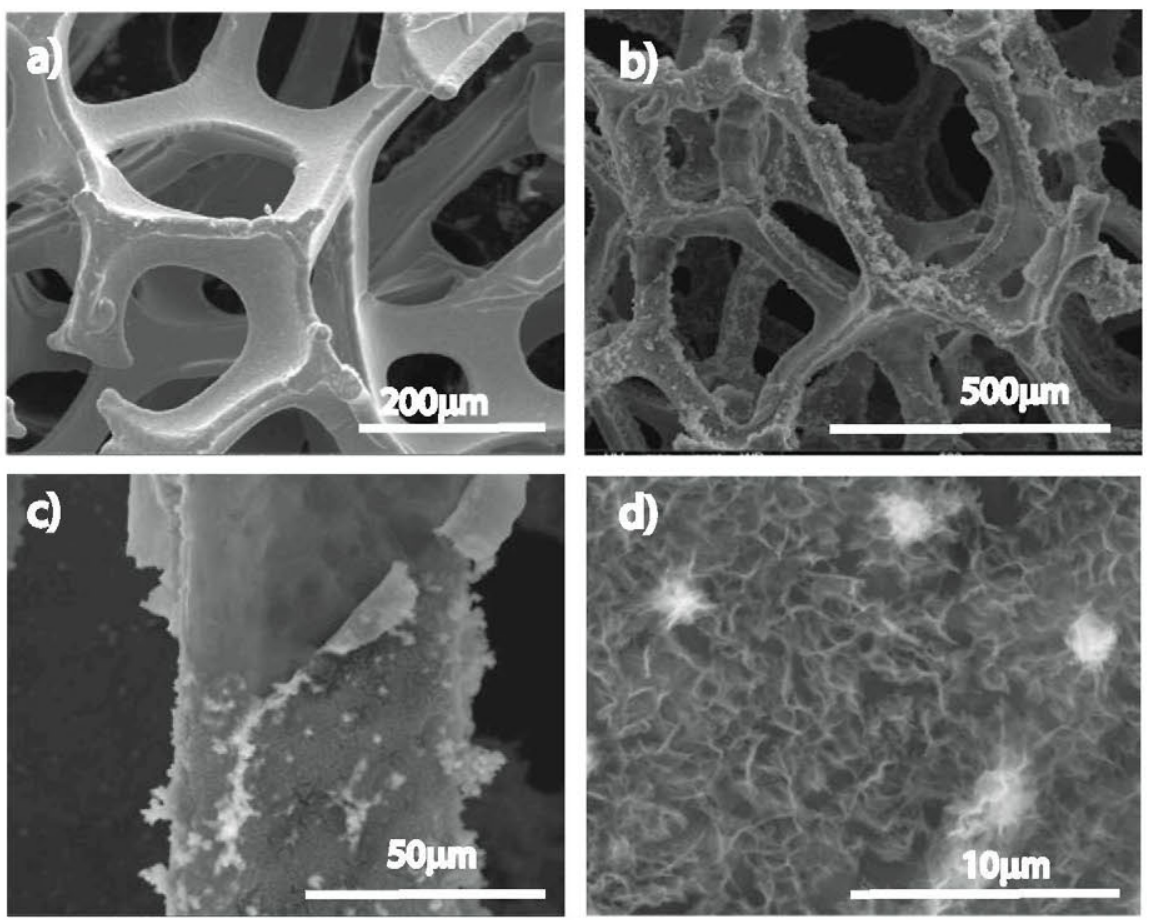

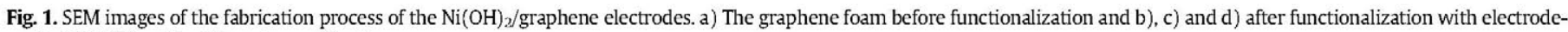
posited $\mathrm{Ni}(\mathrm{OH})_{2}$ with different magnification. 


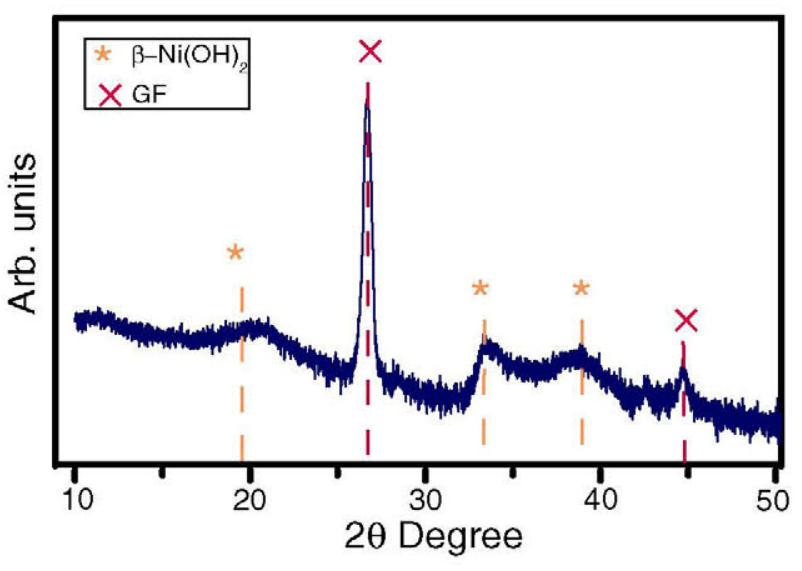

Fig. 2. XRD spectrum of a $\mathrm{Ni}(\mathrm{OH}) 2$ /graphene foam electrode in which reflections from both graphene foam (red crosses) and $\mathrm{Ni}(\mathrm{OH})_{2}$ (yellow stars) can be observed. The structure of the $\mathrm{Ni}(\mathrm{OH})_{2}$ can be indexed as $\beta-\mathrm{Ni}(\mathrm{OH})_{2}$ ( $\left.\mathrm{cod}: 00-014-0017\right)$. (For interpretation of the references to color in this figure legend, the reader is referred to the web version of this article.)

thermal treatment is given to the electrodes after the functionalization. Therefore, the foam and their contacts are kept at low temperature during the whole functionalization process.

A typical XRD pattern of a functionalized electrode is shown in Fig. 2. The spectrum shows two series of peaks: one, marked with red crosses, can be indexed as graphite (cod: 01-089-8487) and the other, marked with orange stars, can be indexed as $\beta-\mathrm{Ni}(\mathrm{OH})_{2}$ (cod: 00-014-0017). The broadening of the peaks in XRD pattern is closely related to the small crystalline size of the $\mathrm{Ni}(\mathrm{OH})_{2}$ nanoflakes that cover the foam. These hydroxide nanostructures have already shown a high electrochemical activity on multiwalled carbon nanotubes [32].

Cyclic voltammograms (CV) and galvanostatic charge/discharge measurements have been used to evaluate the electrochemical behavior of the electrodes. Fig. 3.a shows the CV for a functionalized electrode $(4 \mathrm{~h})$ measured at different scan rates from 5 to $20 \mathrm{mV} \mathrm{s}^{-1}$ in the potential range of $0-0.5 \mathrm{~V}$ ( $\mathrm{vs}$. $\mathrm{Ag} / \mathrm{AgCl}$ ). All the curves have a pair of redox peaks suggesting that the specific capacitance of $\mathrm{Ni}(\mathrm{OH})_{2}$ / graphene foam is primarily due to pseudocapacitance. For a $\mathrm{Ni}(\mathrm{OH})_{2}$ electrode, it is well-accepted that the surface redox reaction is the following [22]:

$\mathrm{Ni}(\mathrm{OH})_{2}+\mathrm{OH}^{-} \rightarrow \mathrm{NiOOH}+\mathrm{H}_{2} \mathrm{O}+\mathrm{e}^{-}$.

According to this reaction, the anodic peak (positive current density) at around $0.45 \mathrm{~V}$ (vs. $\mathrm{Ag} / \mathrm{AgCl}$ ) is attributed to the oxidation of $\mathrm{Ni}(\mathrm{OH})_{2}$ to $\mathrm{NiOOH}$, while the cathodic peak (negative current density) at around $0.15 \mathrm{~V}$ (vs. $\mathrm{Ag} / \mathrm{AgCl}$ ) is related to the reverse reduction process. From Fig. 3.a it is clear that, when the scan rate is increased, the current increases and the reduction peak shifts towards more negative values (shift marked with an arrow in the figure). This shift is due to the increase of the internal diffusion resistance within the pseudocapacitive material that normally happens with an increase in scan rate [33,34].

Fig. 3.b compares the galvanostatic charge/discharge curves measured in a potential window from $0 \mathrm{~V}$ to $0.4 \mathrm{~V}$ at specific currents (from $1 \mathrm{~A} / \mathrm{g}$ to $10 \mathrm{~A} / \mathrm{g}$ ) in $3 \mathrm{M} \mathrm{KOH}$ electrolyte for the graphene foam functionalized with $\mathrm{Ni}(\mathrm{OH})_{2}$ for $4 \mathrm{~h}$. The curves show a pair of small plateaus starting and finishing at potential values close to the peaks seen in the voltammograms (Fig. 3.a).

The charging time and, therefore, the capacitance decrease while increasing the current as expected. Considering that the largest measured value $(\mathrm{t} \sim 1250 \mathrm{~s}$ ) corresponds to a current of $1 \mathrm{~A} / \mathrm{g}$, we have chosen this value of the specific current to compare between the different functionalized electrodes. Fig. 3.c compares the electrochemical performance of the different $\mathrm{Ni}(\mathrm{OH})_{2} /$ graphene composites. From the figure it is clear

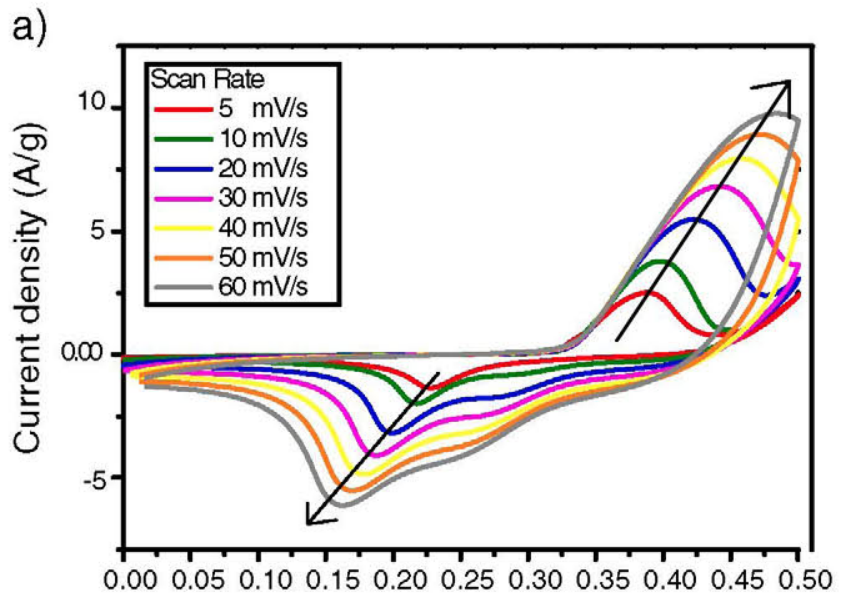

Potential (V) Vs Ag/AgCl (V)
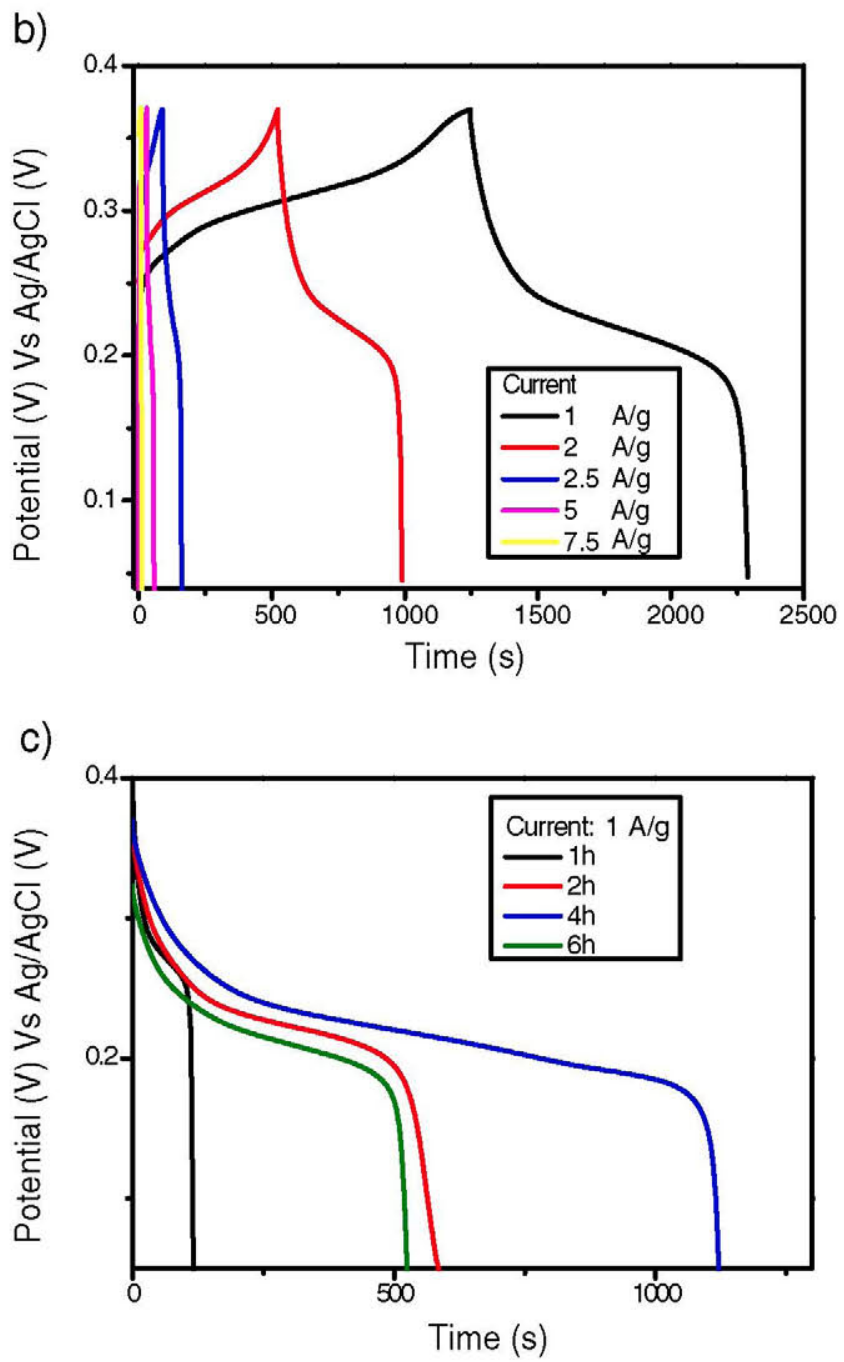

Fig. 3. a) Cyclic voltammograms measured at different scan rates in an electrode functionalized for $4 \mathrm{~h}$. b) Charge/discharge curves measured with different currents for the same electrode. c) Discharge curves measured at $1 \mathrm{~A} / \mathrm{g}$ for the different synthesization-time electrodes.

that the discharging time and, therefore the specific capacitance, increases with the functionalization time up to $4 \mathrm{~h}$. Afterwards, the capacitance and the performance of the electrode degrade with larger 
functionalization time. This is probably due to a blocking of the electrodeposition process. After $4 \mathrm{~h}$, the thickness of the coating starts to be too wide and the ohmic drop too large for the electrodeposition process and, therefore, the electrodeposition stops and the electrode starts to degrade.

The specific capacitance can be calculated from the galvanostatic discharge curves shown in Fig. 3.c, using the following equation [35]:

$C_{\text {spe }}=\frac{\mathrm{I} \Delta t}{m \Delta V}$

where I is the current used in the discharge process, $\Delta t$ is the time needed for a full discharge process, $m$ is the mass of the electrode and $\Delta V$ is the voltage drop after a discharge.

Fig. 4.a collects the capacitance for all the synthesized electrodes, calculated from the curves shown in Fig. 3.c. As mentioned before, the electrode functionalized for $4 \mathrm{~h}$ shows the highest value of capacitance, $900 \mathrm{~F} / \mathrm{g}$ at low specific current. Considering that the main contribution to the specific capacitance in these electrodes is the pseudocapacitance, this parameter drops as expected when the specific current increases. The data of two other electrodes have also been included in the figure for comparison: a graphene foam without functionalization (green curve) and an electrode made with commercial activated carbon, Maxsorb (black curve). The specific capacitance of the functionalized electrodes is clearly larger than the one of the graphene foam, showing the importance of the functionalization in the performance of the device.

The Ragone diagrams - specific power as a function of specific energy for all electrodes are shown in Fig. 4.b. The functionalized graphene foam is clearly better than the one without functionalization in terms of both power and energy. In particular, a maximum power of $8.5 \mathrm{~kW} / \mathrm{kg}$ and energy of $11 \mathrm{Wh} / \mathrm{g}$ are reached. Compared with Maxsorb, the functionalized electrodes are better in terms of power and their behavior is similar in terms of energy. Part of this behavior is due to the large specific capacitance, shown in previous figures, and partly due to the low equivalent series resistance (ESR) that these electrodes show (see Fig. 4.c). The contact made in the graphene foam for the electrodeposition process is not degraded during functionalization due to the low temperature process used and, therefore, can be also used as contact electrode, keeping the ESR low and improving the performance of the device. Finally, to test the long-term performance of the electrodes, we have determined the capacitance retention for best electrode after cycling. The capacitance of capacitance is close to $98 \%$ after 3000 cycles at a current density of $2 \mathrm{~A} / \mathrm{g}$.

\section{Conclusions}

In this work we have shown a low-temperature electrochemical route to functionalize graphene foams with $\mathrm{Ni}(\mathrm{OH})_{2}$ to produce electrodes for supercapacitors. This method combines in a single electrode the superior mechanical and electrical properties of graphene and the large specific area of the foam with the large pseudocapacitance of nickel hydroxide. We have shown that no further thermal annealing is needed after electrodeposition to produce electrodes with large specific capacitance. A maximum value of $900 \mathrm{~F} / \mathrm{g}$ has been obtained, two orders of magnitude higher than the graphene foam without functionalization. The functionalized $\mathrm{Ni}(\mathrm{OH})_{2}$ /graphene foam electrodes show electrochemical characteristics that make them potential candidates to be used as electrodes in supercapacitors.

\section{Prime novelty statement}

The manuscript describes for the first time a low temperature route (without thermal annealing) for the functionalization of graphene foams with electrodeposited nickel hydroxide to be used as electrodes
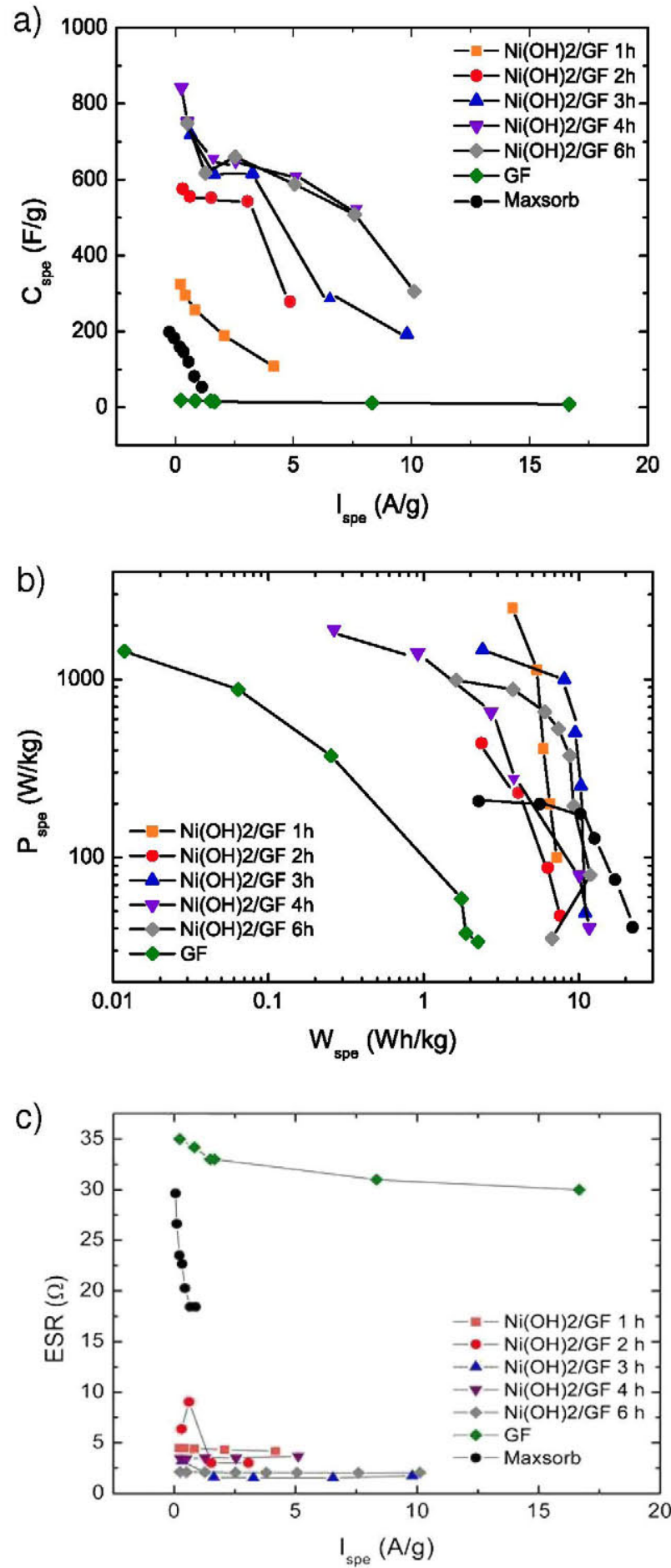

Fig. 4. (a) Specific capacitance retention with increasing specific current, (b) Ragone diagram and (c) equivalent series resistance for the different electrodes synthesized in this work. A graphene foam without functionalization (GF) and an electrode made with commercial active carbon (Maxsorb) are also included for comparison. (For interpretation of the references to color in this figure legend, the reader is referred to the web version of this article.)

for supercapacitors. The reported electrodes show specific capacitance up to $900 \mathrm{~F} / \mathrm{g}$, with specific energy and power comparable to active carbon electrodes.

\section{Acknowledgments}

We thank J. Velázquez, from the C.A.I. de Difracción de Rayos X de la Universidad Complutense de Madrid, for XRD measurements and 
J.M. Rojo y V. Barranco from Instituto de Ciencia de Materiales de Madrid (CSIC) for the measurements on Maxsorb electrodes. This research was supported by Repsol under the Inspire program.

\section{References}

[1] J. Yan, Z. Fan, W. Sun, G. Ning, T. Wei, Q. Zhang, R. Zhang, L. Zhi, F. Wei, Advanced asymmetric supercapacitors based on $\mathrm{Ni}(\mathrm{OH})_{2} /$ graphene and porous graphene electrodes with high energy density, Adv. Funct. Mater. 22 (2012) 2632-2641.

[2] G.R. Fu, Z. Hu, L. Xie, X. Jin, Y. Xie, Y. Wang, Z. Zhang, Y. Yang, H. Wu, Electrodeposition of nickel hydroxide films on nickel foil and its electrochemical performances for supercapacitor, Int. J. Electrochem. Sci. 4 (2009) 1052-1062.

[3] L. Bao, J. Zang, X. Li, Flexible $\mathrm{Zn}_{2} \mathrm{SnO}_{4} / \mathrm{MnO}_{2}$ core/shell nanocable-carbon microfiber hybrid composites for high-performance supercapacitor electrodes, Nano Lett. 11 (2011) 1215-1220.

[4] Z. Fan, J. Yan, T. Wei, L. Zhi, G. Ning, T.L.F. Wei, Asymmetric supercapacitors based on graphene/ $/ \mathrm{MnO}_{2}$ and activated carbon nanofiber electrodes with high power and energy density, Adv. Funct. Mater. 21 (2011) 2366-2375.

[5] B.E. Conway, Electrochemical Supercapacitors: Scientific Fundamentals and Technological Applications, Kluwer Academic/Plenum, New York, 1999.

[6] C. Liu, F. Li, L.-P. Ma, H.-M. Cheng, Advanced materials for energy storage, Adv. Mater. 22 (2010) E28-E62.

[7] A.S. Aricò, P. Bruce, B. Scrosati, J-M. Tarascon, W. van Schalkwijk, Nanostructured materials for advanced energy conversion and storage devices, Nat. Mater. 4 (2005) 366-377.

[8] P. Simon, Y. Gogotsi, Materials for electrochemical capacitors, Nat. Mater. 7 (2008) $845-854$.

[9] Z.-S. Wu, W. Ren, D.-W. Wang, F. Li, B. Liu, H.-M. Cheng, High energy $\mathrm{MnO}_{2}$ nanowire/graphene and graphene asymmetric electrochemical capacitors, ACS Nano 4 (2010) 5835-5842.

[10] H. Wang, Y.Ling, T. Mirfakhrai, Z. Chen, H.S. Casalongue, H. Dai, Advanced asymmetrical supercapacitors based on graphene hybrid materials, Nano Res. 4 (2011) 729-736.

[11] H. Kim, B.N. Popov, Characterization of hydrous ruthenium oxide/carbon nanocomposite supercapacitors prepared by a colloidal method, J. Power Sources 104 (2004) 52-61

[12] M. Zhi, C. Xiang, J. Li, M. Lia, N. Wu, Nanostructured carbon-metal oxide composites electrodes for supercapacitors: a review, Nanoscale 5 (2013) 72-88.

[13] Z.-S. Wu, G. Zhou, L.-C. Yin, W. Ren, F. Li, H.-M. Cheng, Graphene/metal oxide composite electrode materials for energy storage, Nano Energy 1 (2012) 107-131.

[14] Y. Zhang, G. yin Li, Y. Lv, L. zhen Wang, A. gin Zhang, Y. hua Song, B. li Huang Electrochemical investigation of $\mathrm{MnO}_{2}$ electrode material for supercapacitors, Int. J. Hydrogen Energy 36 (2011) 11760-11766.

[15] G.-W. Yang, C.-L. Xu, H.-L. Li, Electrodeposited nickel hydroxide on nickel foam with ultrahigh capacitance, Chem. Commun. 48 (2008) 6537-6539.

[16] H. Jiang, T. Zhao, C. Li, J. Ma, Hierarchical self-assembly of ultrathin nickel hydroxide nanoflakes for high performance supercapacitors, J. Mater. Chem. 21 (2011) 3818-3823.

[17] Y. Yuan, X. Xia, J. Wu, J. Yang, Y. Chen, S. Guo, Nickel foam supported porous $\mathrm{Ni}(\mathrm{OH})_{2} / \mathrm{NiOOH}$ composite film as advanced pseudocapacitors material, Electrochim. Acta 56 (2011) 2627-2632.
[18] J.W. Long, B. Dunn, D.R. Rolison, H.S. White, Three-dimensional battery architectures, Chem. Rev. 104 (2004) 4463.

[19] G. Che, B.B. Lakshmi, C.R. Martin, E.R. Fisher, Chemical vapor deposition based synthesis of carbon nanotubes and nanofibers using a template method, Chem. Mater. 10 (1998) 260-267.

[20] T. Xue, C.-L. Xu, D.-D. Zhao, X.-H. Lic, H.-L. Li, Electrodeposition of mesoporous manganese dioxide supercapacitor electrodes through self-assembled triblock copolymer templates, J. Power Sources 164 (2007) 953-958.

[21] Z. Sun, X. Lu, A solid state reaction route to anchoring $\mathrm{Ni}(\mathrm{OH})_{2}$ nanoparticles on reduced graphene oxide sheets for supercapacitors, Ind. Eng. Chem. Res. 51 (2012) 9973-9979.

[22] H. Wang, H.S. Casalongue, Y. Liang, H. Dai, $\mathrm{Ni}(\mathrm{OH})_{2}$ nanoplates grown on graphene as advanced electrochemical supercapacitor materials, J. Am. Chem. Soc. 132 (2010) $7472-7477$.

[23] M. Kaempgen, C.K. Chan, J. Ma, Y. Cui, G. Gruner, Printable thin film supercapacitor using single-walled carbon nanotubes, Nano Lett. 9 (2009) 1872-1876.

[24] S. Yin, Y. Zhang, J. Kong, C. Zou, C.M. Li, X. Lu, J. Ma, F.Y.C. Boey, Xiaodong, Assembly of graphene sheets into hierarchical structures for high-performance energy storage, ACS Nano 5 (2011) 3831-3838.

[25] A.K. Geim, K.S. Novoselov, The rise of graphene, Nat. Mater. 6 (2007) 183-191.

[26] L. Wanga, X. Lia, T. Guob, X. Yana, B.K. Tayc, Three-dimensional Ni(OH) ${ }_{2}$ nanoflakes/ graphene/nickel foam electrode with high rate capability for supercapacitor applications, Int. J. Hydrogen Energy 39 (2014) 7876-7884.

[27] C. Ge, Z. Hou, B. He, F. Zeng, J. Cao, Y. Liu, Y. Kuang, Three-dimensional flowerlike nickel oxide supported on graphene sheets as electrode materials for supercapacitors, J. Sol-Gel Sci. Technol. 63 (2012) 146-152.

[28] A. Bello, K. Makgopa, M. Fabiane, D. Dodoo-Ahrin, K.I. Ozoemena, N. Manyala, Chemical adsorption of $\mathrm{NiO}$ nanostructured on nickel foam-graphene for supercapacitor applications, J. Mater. Sci. 48 (2013) 6707-6712.

[29] P. Gomez-Romero, Hybrid organic-inorganic materials - in search of synergic activity, Adv. Mater. 13 (2001) 163-174.

[30] J. Ji, L.... Zhang, H. Ji, Y. Li, X. Zhao, X. Bai, X. Fan, F. Zhang, R.S. Ruoff, Nanoporous $\mathrm{Ni}(\mathrm{OH})_{2}$ thin film on 3d ultrathin-graphite foam for asymmetric supercapacitor, ACS Nano 7 (2013) 6237-6243.

[31] X. Cao, Y. Shi, W. Shi, G. Lu, X. Huang, Q. Yan, Q. Zhang, H. Zhang, Nanoporous $\mathrm{Ni}(\mathrm{OH})_{2}$ thin film on $3 \mathrm{~d}$ ultrathin-graphite foam for asymmetric supercapacitor, Small 7 (2011) 3163-3168.

[32] D.P. Dubal, G.S. Gund, C.D. Lokhande, R. Holze, Decoration of spongelike $\mathrm{Ni}(\mathrm{OH})_{2}$ nanoparticles onto MWCNTs using an easily manipulated chemical protocol for supercapacitors, ACS Appl. Mater. Interfaces 5 (2013) 2446-2454.

[33] U. Patil, K. Gurav, V. Fulari, C. Lokhande, O.S. Joo, "Characterization of honeycomblike" $\beta-\mathrm{NiOH}_{2}$ thin films synthesized by chemical bath deposition method and their supercapacitor applications, J. Power Sources 188 (2009) 338-342.

[34] Q.D. Wu, X.P. Gao, G.R. Li, G.L. Pan, T.Y. Yan, H.Y. Zhu, Microstructure and electrochemical properties of Al-substituted nickel hydroxides modified with $\mathrm{COOOH}$ nanoparticles, J. Phys. Chem. C 11 (2007) 17082-17087.

[35] Meryl D. Stoller, Rodney S. Ruoff, Best practice methods for determining an electrode material's performance for ultracapacitors, Energy Environ. Sci. 3 (2010) 1294-1301. 